\title{
Species-specific defense reactions in escape-from-fear situations
}

\author{
MARY CRAWFORD, FRED MASTERSON, and DIANE WILSON \\ University of Delaware, Newark, Delaware 19711
}

\begin{abstract}
Five experiments are reported in which rats were given CS-shock pairings and then permitted, in the absence of shock, to perform a hurdle-jump response that led to CS offset. In Experiment 1-4, the animals failed to learn the required response. Although several procedural variations were employed, the experimental groups continued to perform no better than backward-conditioned controls. In Experiment 5, some animals were punished for remaining immobile during a single trial at the start of hurdle-jump training. These animals performed significantly better than nonpunished controls and better than any group in Experiments 1-4. The results support the idea that the major role of the CS in escape-from-fear situations is to activate an innate motivational system which chooses between the species-specific defense reactions of freezing and fleeing.
\end{abstract}

The offset of a stimulus previously paired with shock has been traditionally viewed as an important source of reinforcement for avoidance learning (Mowrer, 1947; Schoenfeld, 1950). More recently, apparatus cues have also been viewed as fear CSs, but the offset of the nominal CS is still thought to reduce fear and, in combination with apparatus fear reduction, provide the reinforcement for avoidance learning (McAllister \& McAllister, 1971).

One approach to studying the reinforcing properties of CS offset is to separate the CS offset contingency from the other contingencies in effect in the avoidance situation. Masterson (1970) showed that rats reinforced with CS offset and an opportunity to run to a safe place were able to learn a barpress avoidance task, while those reinforced only with CS offset showed little learning; he concluded that CS offset was not in itself reinforcing, while the opportunity to run to a safe place functioned as a powerful reinforcer. Bolles, Stokes, and Younger (1966) analyzed the relative contributions of CS offset, shock escape, and shock avoidance contingencies to learning in a shuttlebox or a running wheel. CS offset was shown to affect performance much more in the shuttlebox than in the running wheel. Bolles and Grossen (1969) examined learning of avoidance responses with or without a CS offset contingency and showed that lack of the contingency affected learning of some responses more than others. Most importantly, even in cases where CS offset influenced learning, a feedback stimulus in its stead was equally effective. Bolles $(1970,1972)$ argued that these data show that CS offset is not the sole or most important

Requests for reprints should be sent to Mary Crawford, Division of Education and Psychology, Buena Vista College, Storm Lake, lowa 50588. Diane Wilson is now at the Department of Psychology, Indiana State University, Terre Haute, Indiana. factor in reinforcing avoidance learning, but that its efficacy depends on the specific learning situation. In situations where learning is affected, Bolles argues for a safety signal interpretation.

Another way to study the reinforcing properties of CS offset is to use situations in which the potential reinforcement contingencies of shock escape and avoidance are absent. The acquired-drive or escape-from-fear situation pairs the CS and shock independently of the animal's responding and then provides the opportunity for the animal to learn a new response with CS offset contingent on its performance. Since shock is never present in the operant learning phase, the situation provides a clearer test of the reinforcing properties of the CS offset than do avoidance learning situations. In addition, McAllister and McAllister (1962) have shown that fear of the CS can be separated experimentally from apparatus fear, a refinement that would seem to make the acquired-drive experiment ideal for measuring the reward properties of CS of fset.

The original purpose of the research described in this paper was to assess the reward value of CS offset in an escape-from-fear task. This purpose was complicated by difficulties in replicating the basic escape-from-fear phenomenon. In our first four experiments, as well as in numerous exploratory studies, most animals did not learn the required response of crossing a hurdle to terminate an aversive $\mathrm{CS}$. Instead, they remained immobile in the presence of the CS or responded erratically, with no trend toward increasing speed.

Experiment 1 documents our initial investigation of the effects of varying the CS offset contingency on performance in the escape-from-fear situation, and shows the original failure to obtain learning in any of the conditions. Our first assumption was that this failure was due to procedural errors. 
Experiments 2-4 were part of our search for procedures which would enable us to replicate McAllister and McAllister (1962). Experiment 5 describes the procedure which was successful in obtaining reasonable acquisition curves in the escape-from-fear task. However, when the series of experiments is viewed as a whole, the significance of Experiment 5 goes beyond methodological concerns. The results of Experiment 5 suggest that the major role of the CS is to trigger an innate motivational system which selects among high-priority defense reactions.

\section{EXPERIMENT 1}

Experiment 1 used the McAllisters' (1962) refinement of the escape-from-fear situation. The CS offset contingency was abolished for one group of rats by using a trace fear CS, and for another group by delaying CS offset following a response, an application of Bolles and Grossen's (1969) contingency manipulations to the McAllisters' situation.

\section{Method \\ Subjects \\ The subjects were 18 male Wistar rats, 90-110 days old, ob- tained from Rockland Farms, Boyertown, Pennsylvania.}

\begin{abstract}
Apparatus
Conditioning. Two identical conditioning boxes were used to permit training pairs of rats simultaneously. Scientific Prototype A100 rat chambers were fitted with metal dividers so that the inside dimensions of each chamber were $11.43 \times 23.5 \mathrm{~cm}$. One end of each chamber was striped with black plastic tape at the corners to resemble the door in the testing apparatus. A $5.08-\mathrm{cm}$-high strip of sheet metal glued to the same chamber wall at grid level simulated the hurdle. The floor of the chambers consisted of .32-cm-diam stainless steel shock grids spaced $1.43 \mathrm{~cm}$ apart, center to center.

Electric shock was obtained from a 150-K-ohm fixed impedance source (Masterson \& Campbell, 1972) and scrambled separately in each chamber by a 12-position switch stepped 4 times/sec. One pole of the source was connected to the walls of each chamber. Shock intensity was $164 \mathrm{~V}$.

Testing. The hurdle-jump apparatus consisted of a startbox and a safe box separated by a manually operated guillotine door. The startbox was a Scientific Prototype A100 rat chamber partitioned identically to the conditioning chambers. The door was striped at the edges with black plastic tape and rested on a 5.08-cm-high sheet metal hurdle. Walls and floor of the $30.48 \times 17.78 \times 18.41 \mathrm{~cm}$ safe compartment were of wood, painted black. An infrared photocell was mounted $3.81 \mathrm{~cm}$ past the hurdle.

In both the apparatus, the CS was a light-tone compound originating from the chamber ceiling. The light was provided by a CM 313 bulb; the tone, produced by a Sonalert, had an average sound level of $76 \mathrm{~dB}$. Background noise, CS, and background illumination were fixed at equal intensities in the conditioning and testing apparatus.
\end{abstract}

\section{Procedure}

The rats were run on 6 consecutive days. On Days 1 and 2, each animal was handled for $5 \mathrm{~min}$ and placed in the startbox and the safebox of the hurdle-jump apparatus for $10 \mathrm{~min}$ each, with the door between boxes closed.

On day 3, all subjects received $35 \mathrm{CS}$-shock pairings. For the 12 subjects to be tested under immediate or delayed CS of fset conditions, CS duration was $6 \mathrm{sec}$, with a 2 -sec shock beginning $4 \mathrm{sec}$ after CS onset. For the remaining 6 subjects, to be tested under a trace CS condition, CS duration was $1 / 2 \mathrm{sec}$, with a $2-\mathrm{sec}$ shock beginning $4 \mathrm{sec}$ after $\mathrm{CS}$ onset. For all subjects, the intertrial interval (ITI) was $2 \mathrm{~min}$.

On Day 4, each rat was placed in the conditioning box for $1 \mathrm{~h}$. Neither the CS nor shock was presented during this session; its purpose was to extinguish apparatus fear.

On Days 5 and 6, the animals were tested in the hurdle-jump apparatus. A rat was placed in the startbox, and $10 \mathrm{sec}$ later the door opened simultaneously with CS onset. If the rat ran to the safe compartment, the door was closed and $10 \mathrm{sec}$ later the rat was removed to a soundproofed holding case for the remainder of the ITI. If the subject did not leave the startbox within $60 \mathrm{sec}$, it was removed and placed in the holding case until the next trial began. The subjects were run in pairs, with each being run during the other's ITI. Each subject's ITIs were therefore determined by its partner's latencies, with a range of about $15-65 \mathrm{sec}$.

One group of subjects $(n=6$ ) was run under standard procedures for an acquired drive situation: crossing the hurdle to the safe box resulted in immediate CS offset (Group I). A second group $(n=6)$ was run under identical conditions, except that a crossing to the safe box resulted in a CS offset delayed for $10 \mathrm{sec}$ after the crossing (Group D). For the six subjects trained with a trace CS (Group T), the CS was presented for $1 / 2 \mathrm{sec}$ on each trial, as during training.

All animals were given 25 trials on each of the 2 consecutive testing days. If a subject failed to respond within $60 \mathrm{sec}$ on 10 consecutive trials, testing was terminated and latencies of $60 \mathrm{sec}$ were recorded for the remaining trials.

\section{Results and Discussion}

No evidence of learning was seen in any of the three groups. Figure 1 shows that mean response speeds were low in all groups and that these speeds did not increase over trials. An analysis of variance on the mean response speeds confirmed that on Day 1 the groups did not differ from each other, $F(2,15)=2.58$, performance did not change significantly over trials, $\mathrm{F}(4,60)=.19$, and the Groups by Trials interaction was not significant, $F(8,60)=.33$. Analysis of mean response speeds on Day 2 shows a similar pattern; neither the main effects nor the interaction reached significance: Groups $\mathrm{F}(2,15)=.80$; Trials, $\mathrm{F}(4,60)=1.04 ;$ Groups by Trials, $\mathrm{F}(8,60)=$ 78 .

The most unexpected finding was that Group 1, trained and tested under conditions typically used in escape-from-fear studies, failed to learn the hurdlejump response. Running speeds were low and showed no tendency to increase over 50 trials. This failure to reproduce a result widely reported in the literature was puzzling: how could animals given $35 \mathrm{CS}$-shock pairings fail to learn a simple response that led to CS offset?

Our first approach to this problem was to make minor procedural changes in the testing phase. The rats had been informally observed during both training and testing and had shown clear behavioral indications of fear. It was therefore assumed that the problem must be one that could be solved by changing some aspects of the testing situation to optimize learning. 


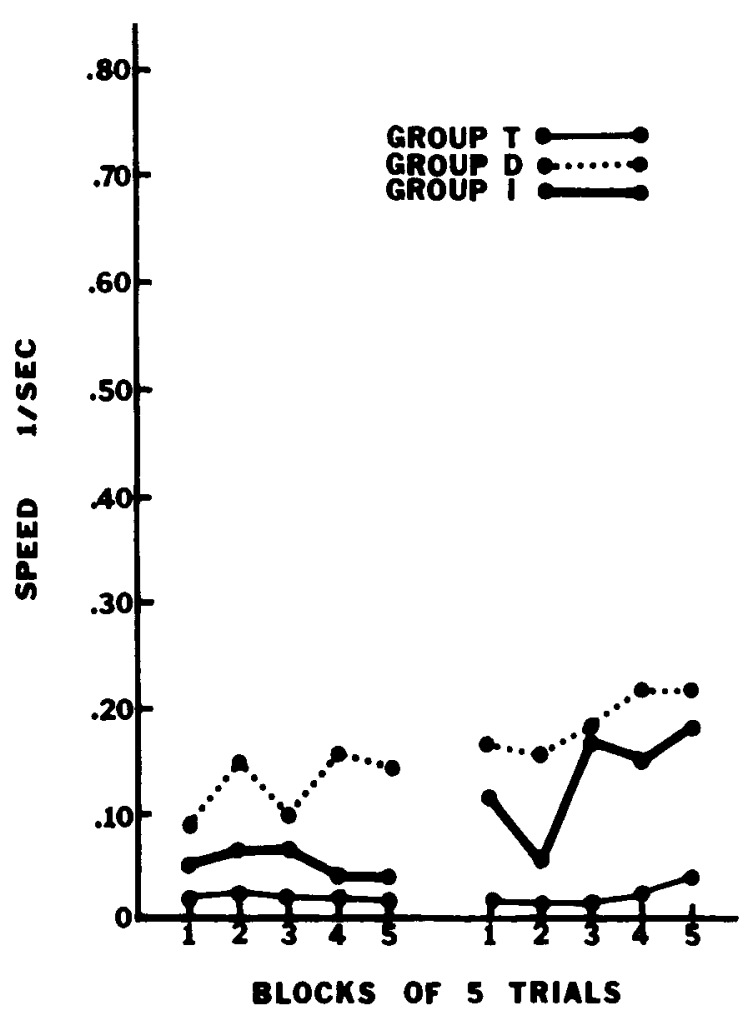

Figure 1. Hurdle-jumping speed as a function of trial blocks on 2 consecutive days for groups tested under trace ( $T$ ), immediate (I), or delayed (D) CS-offset conditions.

We decided to run pilot groups of subjects and to then run larger groups to fully investigate any variable that seemed to have an effect on performance. One group of subjects was run with a 3-sec CS-US interval. A rigorous method of cleaning, ventilating, and disinfecting boxes between each pair of subjects was adopted to minimize the role of olfactory cues. To test for the possibility that subjects could discriminate the training and testing apparatus, some were given the fear conditioning trials in the testing apparatus. Responding in these groups was similar to that of Group I in Experiment 1: there was no evidence for learning of the hurdle-jump response. The one exception was that some subjects trained in the testing apparatus showed a tendency to respond more rapidly than had any previous subjects. This tendency, though not statistically reliable in the pilot group, suggested a trend. We decided to investigate further the effect of differences in training and testing environments.

\section{EXPERIMENT 2}

Similarity of training and testing apparatus has been shown to affect learning in escape-from-fear situations. Immediately after fear conditioning, animals can discriminate between the conditioning box and a highly similar test box (McAllister \& McAllister, 1963), probably on the basis of olfactory cues (King, 1969). As time between training and testing increases, fear generalizes and animals typically learn the hurdle-jump response even if training and testing apparatus are dissimilar. A period of $48 \mathrm{~h}$ intervened between training and testing in Experiment 1 . It would seem unlikely that the rats discriminated the two highly similar boxes after such an interval. Furthermore, apparatus fear was extinguished during this time. The theoretical basis for including an apparatus fear extinction session was that such fear is separable from CS fear and that its elimination allows a pure test of CS fear. Though it seemed implausible that the failure to learn in Experiment 1 was due to the differences in the training and testing chambers, we tested this explanation directly because the pilot work had revealed a trend toward learning when animals were trained and tested in the same chamber.

\section{Subjects \\ Method \\ The 16 subjects were identical to those used in Experiment 1 .}

\begin{abstract}
Apparatus
The apparatus was the same as used in Experiment 1. Half of the subjects were fear conditioned in the training apparatus and half in the testing apparatus, from which the safe compartment was detached during conditioning.
\end{abstract}

\section{Procedure}

With the exception that half the subjects were conditioned and tested in the same apparatus, all experimental procedures were identical to the treatment given Group I in Experiment 1. The subjects were run on 6 consecutive days. Following handling and adaptation to the testing apparatus on Days 1 and 2 , the subjects were given 35 fear-conditioning trials (Day 3 ) in pairs in the conditioning apparatus (Group $B A, n=8$ ), or singly in the testing apparatus (Group $\mathrm{AA}, \mathrm{n}=8$ ). $\mathrm{CS}$ duration was $6 \mathrm{sec}$, with a 2 -sec shock beginning $4 \mathrm{sec}$ after CS onset. Shock source and intensity were the same as in Experiment 1. Apparatus fear extinction, a 1-h session on Day 4, was given in the chamber in which each subject had been trained. On Days 5 and 6, the subjects were given 25 hurdle-jump trials in the testing apparatus. Crossing to the safe compartment resulted in immediate CS offset for all subjects, followed by removal to a soundproofed holding box after $10 \mathrm{sec}$. Provisions for terminating a trial and a session were the same as in Experiment 1.

\section{Results and Discussion}

Conditioning in the same or a different apparatus had no effect on performance during testing. Figure 2 indicates that Group AA and BA did not differ on either test day. This was confirmed by analyses of variance which showed that the Group effects for Day $1, F(1,14)=.52$, and Day 2, $F(1,14)=.15$, were not significant.

Figure 2 also indicates a trend toward increasing running speed in both groups on Day 1. This trend approached, but did not reach, statistical significance, $F(4,56)=2.47, p<.054$. However, the increase in speed did not carry over to Day 2; instead, performance over trials was poor in both groups, $F(4,56)=.16$. The Groups by Trials interaction did 


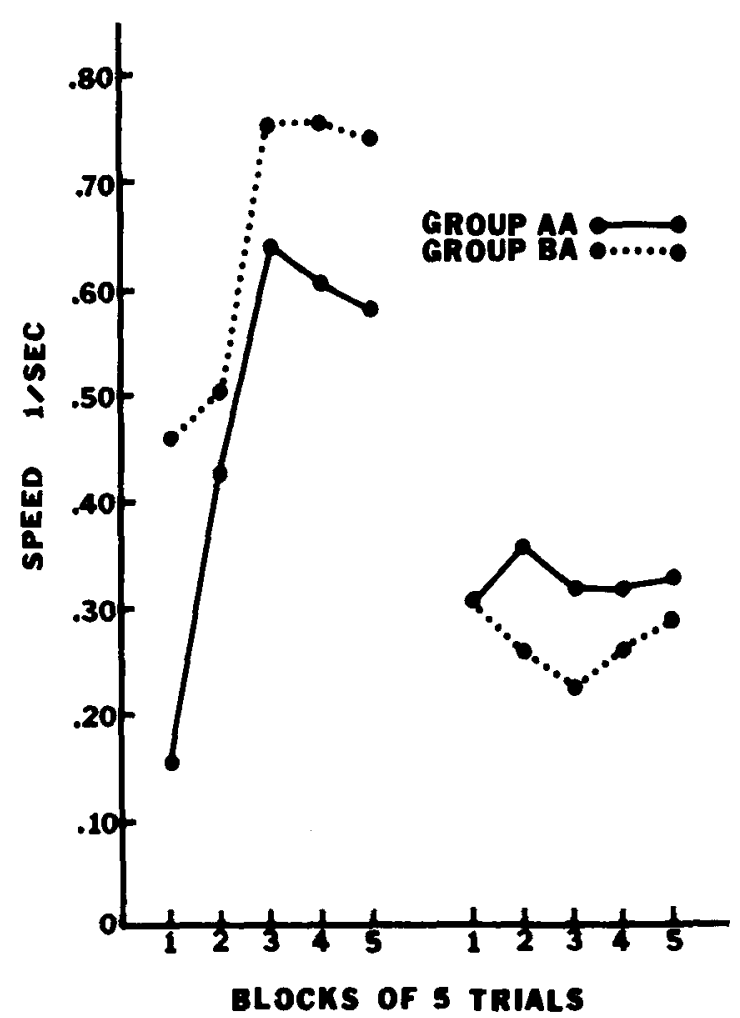

Figure 2. Hurdle-jumping speed as a function of trial blocks when the same (AA) or different (BA) chambers were used for conditioning and testing.

not reach significance on either Day $1, F(4,56)=.18$, or Day $2, F(4,56)=.26$.

The trend toward increasing speeds on Day 1, while not statistically significant, and not repeated on Day 2, was the closest approximation to learning that we had yet obtained. We therefore ran another group of animals under conditions identical to those in Group AA, where the trend was most obvious. The results were disappointingly similar to those of Experiment 1. It became evident that we had not yet found the ideal parameters for obtaining learning in the escape-from-fear situation.

\section{EXPERIMENT 3}

The discriminability of training and testing apparatus had proved not to be the factor inhibiting learning. Again, pilot work was done in an attempt to isolate variables for further study. The light CS was eliminated, leaving only the tone. The time between training and testing was reduced by giving training, apparatus fear extinction, and testing on the same day. Advice from researchers familiar with the acquired-drive situation (McAllister \& McAllister, personal communication) led to the use of female hooded rats instead of male Wistars, painting the safe box gray, and a careful control of room temperature. Though a total of 51 animals was run, the results showed no clear trend. The first author, after visiting a laboratory where acquired-drive experiments were in progress, made further attempts to set up a situation in which learning would occur. These efforts, conducted at the University of Illinois, included running subjects in which no attempt was made to eliminate apparatus fear, varying the brightness of both compartments, varying the shock source and intensity, and using both male and female subjects of a third strain (Sprague-Dawley derived, bred at the University of Illinois animal colonies). None of these efforts were successful.

Meanwhile, the second author continued to supervise work on the problem at the University of Delaware. The eventual goal remained that of testing the reward effects of CS effect in the acquireddrive situation by comparing delayed and immediate CS offset groups. With that goal in mind, a preliminary study was needed to assess the effect of the presence of the CS in the safe box. Given immediate CS offset following a response, would the presence of the CS in the safe box preceding the response affect performance?

Experiment 3 also reflects our continuing attempts to obtain reliable learning in the hurdle-jump situation. The apparatus-fear extinction session was eliminated in order to maximize fear and thus increase the probability of learning. A backwardconditioned control group was added for each experimental condition. Finally, the animals in this experiment and Experiment 4 were run by a naive experimenter who was unaware of our previous failures to obtain learning with this task.

\section{Subjects}

\section{Method}

The 24 rats were identical to those used in Experiments 1 and 2 , and were randomly assigned to four groups of 6 .

\begin{abstract}
Apparatus
The testing apparatus was modified to present a tone CS in both start and safe boxes or in the startbox only. The light CS used in the previous experiments was removed. Three $6.35-\mathrm{cm}$ AR43 speakers wired in parallel were attached to the inside of each chamber lid and covered with wire mesh. Average CS level was $80 \mathrm{~dB} \mathrm{SPL}$, as measured inside the apparatus. An identical system for CS presentation was installed in each conditioning chamber.
\end{abstract}

\section{Procedure}

Handling, on Days 1 and 2, was increased to $10 \mathrm{~min}$, followed by $10 \mathrm{~min}$ adaptation to each side of the testing apparatus. On Day 3, all subjects received 35 fear-conditioning trials in the training apparatus. Half the subjects were forward-conditioned, with a 6-sec CS joined after $4 \mathrm{sec}$ by a 2 -sec shock. Half the subjects were backward-conditioned, with the US preceding the $\mathrm{CS}$ by an interval of $15 \mathrm{sec}$ on each trial. Shock source and intensity and the ITI were the same as in the previous experiments. The apparatus-fear extinction session was eliminated; testing therefore occurred on Days 4 and 5. For one forward-conditioned and one backward-conditioned group, the CS was present in the startbox (Groups FC-S and BC-S). For the other two groups, one forward-and one backward-conditioned, the CS was present in both the start and safe boxes at the beginning of each trial (Groups FC-B and BC-B). For all groups, a hurdle-jump response 
led to immediate CS offset. As in the previous experiments, each rat was run for 25 test trials on each of 2 consecutive days. The ITI during testing and provisions for terminating a trial and a session were the same as in Experiments 1 and 2.

\section{Results and Discussion}

The presence of the CS in the safe compartment of the apparatus did not affect performance. An analysis of variance showed that CS location did not have a significant effect on either Day $1, F(1,20)=$ 2.08 , or Day 2, $F(1,20)=2.38$.

Figure 3 shows that performance was poor in all groups. The erratic responding observed in earlier experiments persisted in spite of changes in procedure. The forward-conditioned groups did not, in fact, differ significantly from the backwardconditioned groups on either Day $1, \mathrm{~F}(1,20)=.008$, or Day 2, $F(1,20)=1.35$. Performance did not change over trials on Day $1, F(4,80)=.61$. The significant change across trials on Day $2, F(4,80)=$ $6.05, \mathrm{p}<.001$, reflects the decreasing running speeds of all groups. None of the interactions were significant.

Eliminating the extinction of apparatus fear and introducing a naive experimenter into the situation had failed to improve performance. Our experimental animals still were learning no better than backward-conditioned controls.

\section{EXPERIMENT 4}

One variable we had not yet thoroughly investigated was the CS-US interval. In Experiments 1-3 and most of the pilot work, this interval was constant. It is possible that the animals learned to "time out" the interval during the 35 conditioning trials. If so, fear might extinguish rapidly during testing when shock did not occur on schedule. Rapid extinction of conditioned fear could have been the cause of the erratic responding we had observed. In Experiment 4, the CS-US interval was made variable during conditioning.

\section{Method}

Subjects

The 32 rats were identical to those used in Experiments 1-3.

\begin{abstract}
Apparatus
The conditioning and testing apparatus were the same as in Experiment 3, with the single exception that the tone CS was replaced by a white noise provided by a Grason-Stadler noise generator, Model 901B. The average CS level was $80 \mathrm{~dB}$ SPL, measured from inside the apparatus.
\end{abstract}

\section{Procedure}

Handling (Days 1 and 2) was identical to that in Experiment 3. On Day 3, all subjects received 35 fear-conditioning trials in the training apparatus. The CS.US interval varied from 7.5 to $60 \mathrm{sec}$, with a mean interval of $28 \mathrm{sec}$. The ITI was $2 \mathrm{~min}$. Half the animals (Group FC) were forward-conditioned and half (Group BC) were backward-conditioned, with the US preceding the $C S$ by an interval of $15 \mathrm{sec}$ on each trial. On Days 4 and 5 .

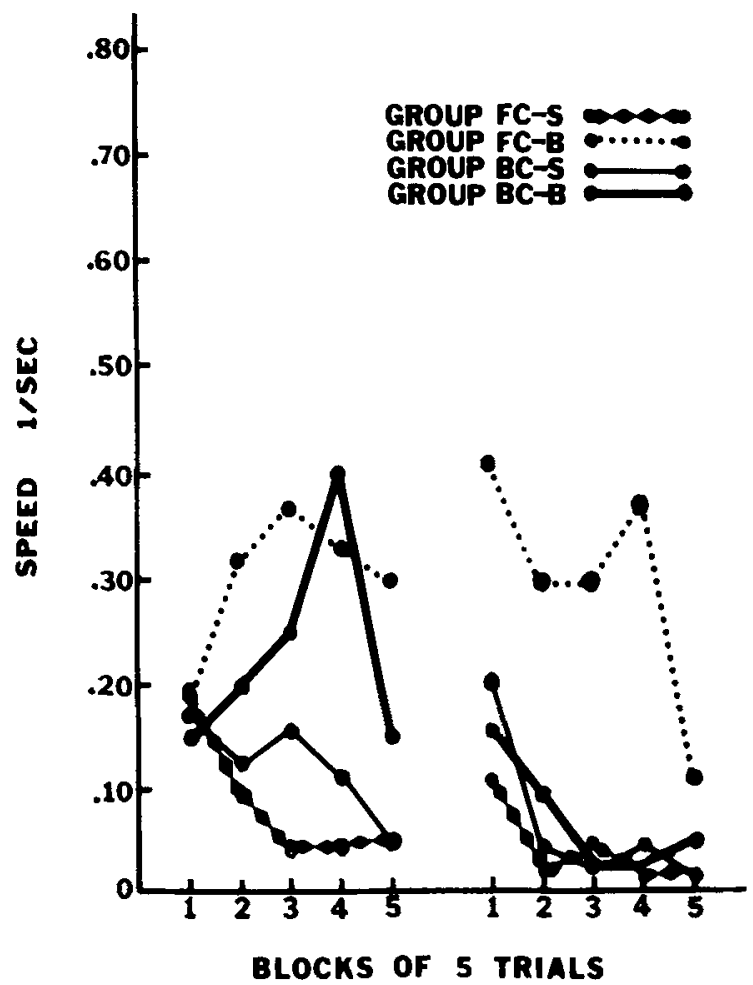

Figure 3. Hurdle-jumping speed as a function of trial blocks for groups given forward-conditioning and tested with the CS present in the starting compartment only (FC-S) or with the CS preseni in both compariments (FC-B), and for corresponding backward-conditioned control groups (BC-S and BC-B).

the subjects were given 25 test trials in the testing apparatus. The CS was presented in the startbox only for all subjects.

\section{Results and Discussion}

The use of a variable CS-US interval did not produce better performance than the constant interval used in previous experiments. Figure 4 shows that running speeds were low, that there was no tendency for speed to increase over trials, and that the forwardand backward-conditioned groups did not appear to differ from each other. These results were confirmed by analyses of variance on mean speeds over blocks of five trials. The F values of Day 1 and Day 2 were as follows: Groups, $F(1,30)-.02$ and .03 , Trials, $F(4,120)=1.22$ and 5.22, Groups by Trials, $F(4,120)=.85$ and .49 . Of all thse values, only the Trials effect for Day 2 reached significance $(p<.001)$, and it reflects a decrease in speed.

In spite of considerable experience with this task, we remained unable to produce any better performance with forward-conditioning than with backward-conditioning, and we seemed to be no closer to finding the reason. The most salient effect of Experiments 3 and 4, it seemed, had been to convert our naive experimenter into a thoroughly nonnaive one!

In summary, systematic efforts by three researchers over a period of 2 years to investigate many 


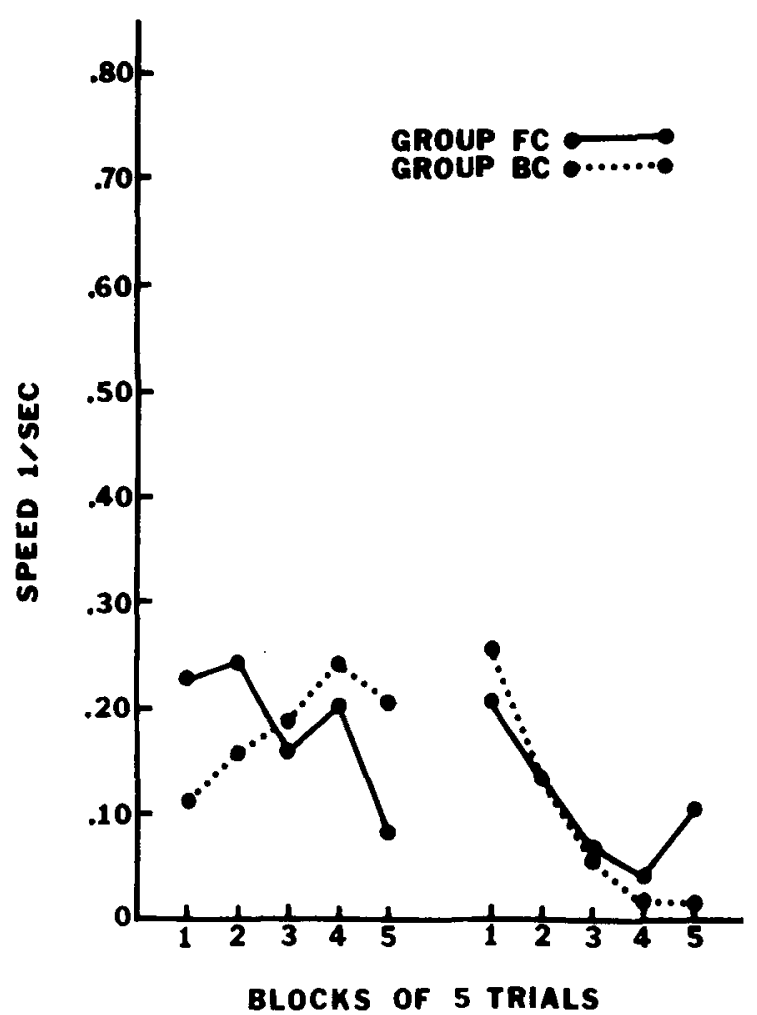

Figure 4. Hurdle-jumping speed as a function of trial blocks for forward-conditioned (FC) and backward-conditioned (BC) rats when both groups were conditioned and tested with a variablelength CS.

variables which might affect learning in escape-fromfear situations resulted in consistent failure to produce anything that could be described as "learning-a-new-response-which-is-reinforced-byCS-offset." Many animals failed to respond, remaining immobile during CS presentation. Some responded erratically. Some did show the rapid responding on early trials and the decreasing latencies on subsequent trials that have been reported elsewhere; but whether or not an animal would respond and "learn" remained unpredictable.

Early investigators of the escape-from-fear situation also reported problems with failures to learn. In Miller's (1948) study, often cited as the original demonstration of the escape-from-fear phenomenon, all animals learned to run from a shock compartment to a safe compartment. It is generally overlooked that in this phase of the experiment shock was not presented independently of the opportunity to flee the compartment. After the first trial, in which subjects were shocked every $5 \mathrm{sec}$ for $60 \mathrm{sec}$, then permitted to escape continuous shock, each trial was in fact an escape trial, with shock onset occurring before the door opened and shock of fset providing primary negative reinforcement. Only five nonshock trials were given following escape training before subjects were required to learn the new response of turning a wheel to allow escape to the safe compartment. Twelve of the 25 subjects failed to learn the new response. Those that failed, reported Miller, tended to crouch motionless, and to do so earlier on successive trials. Thus, in spite of the fact that previous escape training was given, freezing remained about as probable as turning a wheel to escape the compartment. It was suggested that "Apparently crouching occupies a dominant position in the innate hierarchy of response to fear." In another early study, Brown and Jacobs' (1949) animals were significantly slower to respond than nonshocked controls early in training (Experiment 1); this was attributed to their tendency to become immobile at CS onset. It was suggested that the fear drive "acts to intensify whatever response is dominant at the moment, whether it be a response of crouching or one of a more active variety." The authors mention Miller's suggestion that crouching is likely to be a dominant response in fearful animals because it is high in the hierarchy of innate responses to fear. More recently, Miller and Weiss (1969) have discussed the freezing problem at length and described techniques for modifying the response hierarchy.

The repeated failure of animals to learn the escape-from-fear response suggests two possible conclusions. One is that conditioning and testing procedures have been less than optimal. This argument loses force when animals have been trained and tested under a wide variety of conditions. A second possibility, and one that is consistent with evidence from avoidance learning, is that CS offset does not provide effective reinforcement for learning in this situation.

Animals do, however, learn, both in avoidance tasks and escape-from-fear tasks; at least, they sometimes come to perform the required response. If the reinforcing properties of CS offset are not responsible, what is the mechanism underlying such learning? The problem is to explain both cases of learning and cases of failures to learn. Bolles (1970, 1972) has proposed that learning in any fear-eliciting situation is under strong constraints imposed by the animal's species-specific defense reactions (SSDRs). He suggests that SSDRs for the rat are freezing, fleeing and possibly aggression. When the required response in an aversive learning situation is some variation of an SSDR, learning will be rapid. The mechanism underlying such learning, Bolles proposes, is the suppression of competing SSDRs through punishment. When the required response is not an SSDR, learning will be slow and uncertain. This formulation readily explains the continuum of difficulty in avoidance learning tasks. It is also consistent with the evidence cited earlier that CS offset is not in itself a powerful reinforcer.

Bolles' theory also has applications to escapefrom-fear tasks. Consider the rat that has received many pairings of a CS and shock in a situation where 
no response, SSDR or other, has any effect on shock occurrence. Flight, in the sense of leaving the feareliciting situation, is impossible, and any attempts are punished. Freezing can occur, but it is also consistently punished. When an animal is later put into an escape-from-fear test situation, whichever SSDR happens to occur first should tend to persist. Neither freezing nor fleeing is punished in the test situation. From the rat's point of view, both are effective SSDRs.

The SSDR hypothesis can account for the variability in performance seen in the present experiments and others (Brown \& Jacobs, 1949; Miller, 1948). It makes a clear prediction for the escapefrom-fear task: if the freezing SSDR is dominant when testing begins, its punishment will lead to the emergence of the fleeing SSDR and thus to learning of the "correct" hurdle-jump response. This prediction is tested in the following experiment.

\section{EXPERIMENT 5}

The basic problem in Experiments 1-4 and in the pilot groups was that many animals remained immobile during CS presentation. Of the animals that did respond early in testing, some continued to respond on subsequent trials and some reverted to immobility. If CS offset were an effective reinforcer, at least those animals that did respond should have continued to do so after the reinforcement contingency was applied. In addition, the CS-offset hypothesis cannot explain why freezing, which was never reinforced, should occur in so many animals and should be so remarkably persistent.

The SSDR prediction for the escape-from-fear task is that whichever SSDR happens to occur on early trials is likely to persist. Either is "effective" for the fearful rat, since no shock will occur regardless of which response mode the animal adopts. Since no shock ever occurs during testing to suppress either SSDR, some animals might alternate between the two responses.

Experiment 5 was designed to show that punishing one SSDR, freezing, would rapidly suppress it. Animals would then employ the fleeing SSDR and run to the safe compartment.

\section{Method}

\section{General Design}

Three groups of rats were given CS-shock pairings followed by testing in the hurdle-jump apparatus. One group's test trials were the standard type for an escape-from-fear task: on each trial, the door was opened, the CS was presented, and the rat had the opportunity to run to the safe compartment and terminate the CS. This standard conditioning group was labeled Group C. Testing conditions were identical for the other two groups except for the contingencies in effect on a single interpolated trial at the start of testing. For one of these groups, the interpolated trial began with CS onset, followed $7 \mathrm{sec}$ later by the simultaneous onset of shock and raising of the door between compartments.
The animal could escape shock at any time after its onset by running to the safe compartment. This group, given prior conditioning and an escapable shock trial, was labeled Group C-E. For the other group (Group C-I), the interpolated trial began with CS onset, followed $7 \mathrm{sec}$ later by the onset of a $2-\mathrm{sec}$ inescapable shock. The door was raised immediately after shock offset and the animal could then run to the safe compartment.

It is probable that the escape contingency in effect on Trial 1 for Group C-E would contribute to the strength of the running response-e.g., that any learning in this group might be the result of the escape trial rather than the prior fear conditioning trials. To control for this possibility, an additional group was run which received the single escape trial and subsequent testing but no prior fear conditioning (Group NC-E). Similarly, it is possible that any learning demonstrated by Group C-I could be the result of the single CS-shock pairing in the hurdle-jump apparatus rather than the prior fear conditioning trials; accordingly, a group (Group NC-1) was run in which subjects received treatment identical to that of Group C-I, except that they had been given no prior fear conditioning.

Following the single trial in which the punishment of freezing was manipulated, all groups were given 25 trials in the hurdlejump apparatus on each of 2 consecutive days. The single interpolated trial was not included in analyses of test trials. The prediction, stemming from the SSDR hypothesis, was that Groups C-E and C-I, in which the freezing SSDR was punished, would learn the hurdle-jump response significantly better than the other groups.

\section{Subjects}

The 40 subjects were male Wistar rats identical to those used in Experiments 1-4, assigned randomly to groups.

\section{Apparatus}

Apparatus and conditioning procedures were identical to the forward conditioning used in Experiment 4.

\section{Procedure}

All subjects were handled on 2 consecutive days. Those in Groups C, C-E, and C-I then received, on Day 3, 35 fearconditioning trials, with a CS-US interval varying from 7.5 to $60 \mathrm{sec}$ around a mean of $28 \mathrm{sec}$. The ITI was $2 \mathrm{~min}$. Conditioning took place in the conditioning apparatus; the subjects were run in pairs. Group NC-E and NC-I rats were placed in the conditioning apparatus in pairs for a time equal to the time required for conditioning, but were never exposed to the CS or to shock.

Testing was conducted on Days 4 and 5 in the testing apparatus. Group $C$ was tested under standard conditions identical to Group FC, Experiment 4. The other four groups received a single extra trial interpolated at the start of testing on Day 4. The trial began with $\mathrm{CS}$ onset, while the door between compartments remained closed. For subjects in Groups C-E and NC-E, the CS was joined after $7 \mathrm{sec}$ by shock and the door between compartments was raised simultaneously with shock onset. Shock was delivered until the animal terminated both shock and CS by leaving the compartment. For Groups C-I and NC-I, the CS was joined after $7 \mathrm{sec}$ by a 2 -sec shock. The door between compartments was raised immediately following shock of fset, providing the rat with an opportunity to run to the safe compartment. The shock source and intensity used for the interpolated trial were identical to those used in conditioning.

Testing was identical for all five groups following the interpolated trial and followed the procedure described for previous experiments.

\section{Results and Discussion}

The data are consistent with the predictions based on the SSDR hypothesis. The two groups in which freezing was punished on a single trial (Groups C-E 
and $\mathrm{C}-\mathrm{I})$ performed the hurdle-jump response faster than the other three groups (see Figure 5). An analysis of variance on the mean response speeds in blocks of five trials for Day 1 showed significance for the Groups effect, $F(4,35)=6.29, p<.001$; the Trials effect, $F(4,140)=3.88, p<.005$; and the Groups by Trials interaction, $F(16,140)=2.65$, $\mathrm{p}<.001$. A subsequent Newman-Keuls test $(\alpha=.01)$ showed that Groups C-E and C-I did not differ from each other. The standard conditioning group, Group C; did not differ from the two non-fearconditioned control groups, NC-E and NC-1; all were inferior to Groups C-E and C-I.

Similar results were obtained from an analysis of variance on Day 2's mean speeds. The main effects and interactions all reached significance: Groups, $F(4,35)=3.04, p<.02$; Trials, $F(4,140)=4.47$, $\mathrm{p}<.002$; and the Groups by Trials interaction, $F(16,140)=2.16, p<.009$. A Newman-Keuls test $(\alpha=.05)$ showed that the performance of Group C-I was superior to that of the other four groups, which did not differ from each other. The superiority of Group C-I over Group C-E on Day 2 may be attributed to the fact that shock duration was a constant $2 \mathrm{sec}$ for the former. Only one rat in Group C-E received a shock of more than $2 \mathrm{sec}$ duration on the interpolated trial; all others escaped with shorter latencies. Thus, the punishment of freezing was, on the whole, longer in duration for Group C-I, and could be expected to be more effective.

The most striking feature of these results is the effect of punishing freezing on a single trial. In Experiments 1-4, as well as in Group $C$ in this experiment, some animals responded within $60 \mathrm{sec}$ on every trial, thus receiving repeated exposure to the $\mathrm{CS}$ offset contingency. This exposure was almost totally ineffective in changing response probability or latency. But a single exposure to the punishment contingency led to significantly better performance.

The performance of Groups C-E and C-I cannot be attributed to the interpolated trial itself. Groups NC-E and NC-I, run under identical conditions but without previous fear conditioning, performed very poorly and showed no tendency toward increasing speeds. Thus, the prior fear conditioning given Groups $\mathrm{C}-\mathrm{E}$ and $\mathrm{C}-\mathrm{I}$ was instrumental in producing the performance of these groups. Group C, which experienced the fear conditioning but not the punishment-of-freezing trial, showed erratic performance like that of similarly trained animals in Experiments 1-4. It is thus reasonable to conclude that the standard conditioning procedures used in Experiments $1-4$ and for Group $C$ in the present experiment did produce fearful animals. The CSoffset contingency was simply not functioning as a reducer of fear. The relative effectiveness of repeated exposure to CS offset and a single exposure to the punishment contingency suggests that fearful rats are

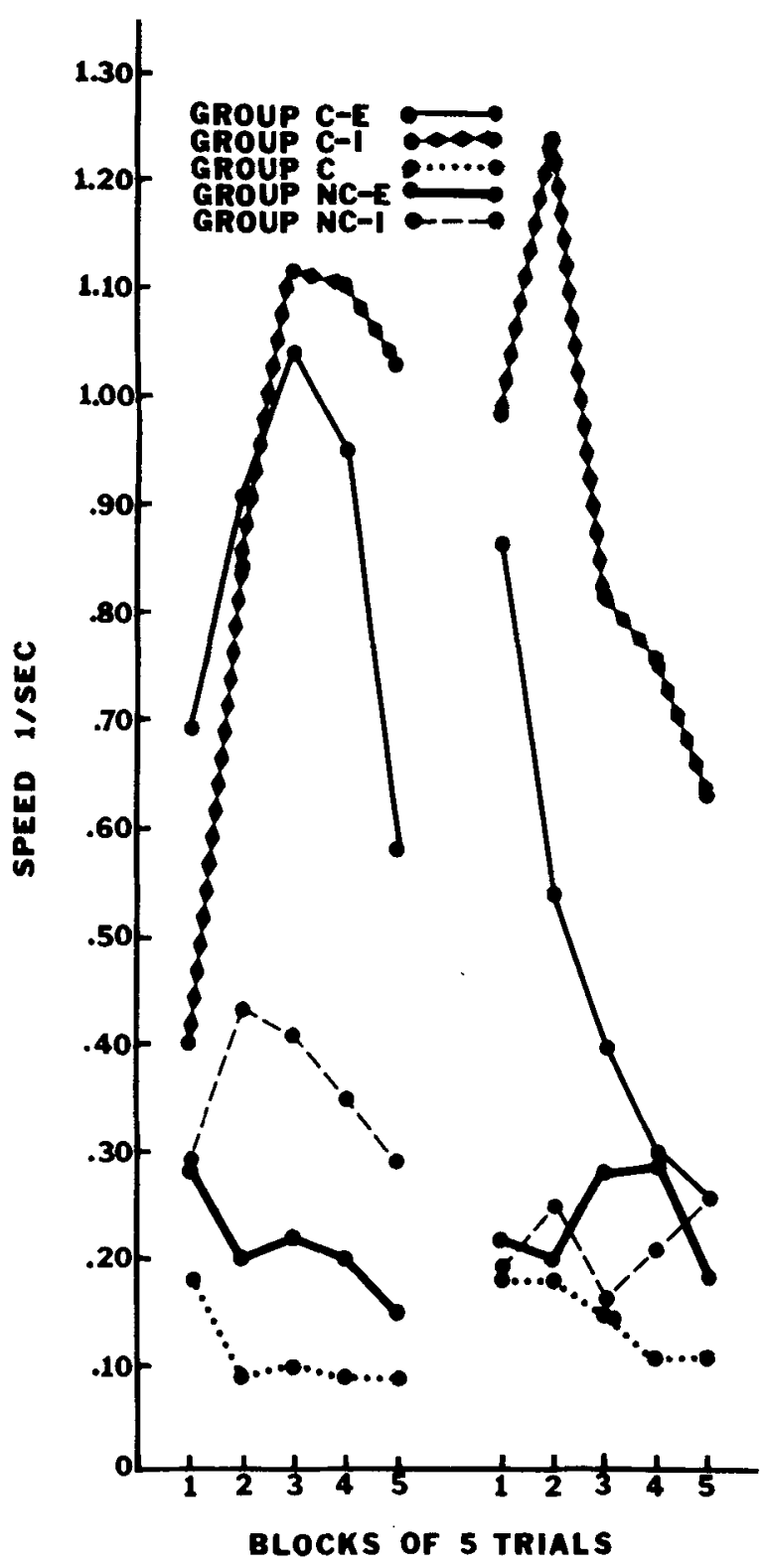

Figure 5. Hurdle-jumping speed as a function of trial blocks when rats had received standard conditioning only $(C)$ or had been, in addition, punished for remaining immobile (C-E and C-I). Control Groups NC-E and NC-I received punishment but no prior fear conditioning.

much more sensitive to the latter, supporting the contention of the SSDR hypothesis that the mechanism underlying learning in many aversive situations is suppression of inappropriate SSDRs through punishment.

\section{GENERAL DISCUSSION}

The escape-from-fear task, though plagued by failures of animals to learn the required response, is widely considered to provide evidence for the reinforcing properties of $\mathrm{CS}$ offset. If failures to learn are regarded as due to inadequate condi- 
tioning or testing procedures, the results of escapefrom-fear studies do tend to support this view. However, the present experiments have shown that failure to learn is a persistent problem, occurring over a wide range of conditioning and testing procedures. It cannot be attributed to a lack of conditioned fear. The three experimental groups in Experiment 5 all received identical fear conditioning; yet, without an added punishment contingency, no effects of the conditioning were observable in performance. The single punishment trial led to superior performance only if prior fear conditioning had been given.

Furthermore, failure to learn cannot be attributed to lack of exposure to the CS offset contingency. If animals typically remained immobile on every trial, it might be argued that the potential reinforcing ability of CS offset remained untested. In Experiments $1-4$, some animals did remain completely immobile. But many more responded on some trials, and some on each of the 50 test trials, without showing the pattern of increasing speed that would have demonstrated learning.

To understand the results of Experiment 5, it is necessary to consider the data without making the assumption that CS offset is an important source of reinforcement. The avoidance situation that corresponds most closely to escape-from-fear tasks is one-way avoidance. Of the commonly used avoidance situations (one-way, wheel-running, shuttlebox, barpress), one-way running is the most rapidly and consistently learned (Santos, 1960; Theios, 1963). It is also the avoidance situation in which CS offset is least essential to learning (Bolles \& Grossen, 1969). In one-way avoidance learning, the required response is an unambiguous SSDR, that of fleeing all situational cues associated with shock. Furthermore, the competing SSDR, freezing, is punished every time it occurs. The role of the CS can be viewed as informational. Its onset tells the rat that fleeing is appropriate, a relatively minor role since other situational cues provide the same information.

The situation has much in common with the escapefrom-fear task. Again, the required response is the SSDR of flight, in a form that allows escape from all shock-associated cues. The onset of the CS signals that flight is appropriate, as does the presence of apparatus cues. There are, however, two crucial differences. In the escape-from-fear task, the animal has had prior experience with shock in which all SSDRs were ineffective. And there is no provision during testing for punishing the freezing SSDR. The onset of CS signals pending shock. If the animal flees, shock does not occur. If the animal freezes, shock likewise does not occur. It is not surprising that performance remains erratic, with neither response predominating.
There is no doubt that the interpolated shock trial in Experiment 5 elicited flight, and that the flight response tended to persist on subsequent nonshock test trials. However, one may question whether the persistance of flight resulted from the punishment of freezing. An alternative explanation is that the shock reactivated the flight SSDR, placing it at the top of the SSDR hierarchy. In other words, flight may emerge as a side effect of the suppression of freezing by shock, or as a direct effect of the unconditional reactivation of flight by shock, or through a combination of these factors. Obviously, the present data do not permit us to discriminate among these hypothetical alternatives.

What are the results of acquired-drive experiments in which the required responses are unrelated to the animal's SSDR? Robinson (1961) and Trapold, Blehert, and Sturm (1965) both used a variation of the acquired-drive task in which rats first learned a shuttle avoidance response and were then confined in the avoidance apparatus and given the opportunity to depress a bar to terminate the CS in the absence of shock. Both studies report rapid learning of the bar-holding response. Their results are ambiguous, however, from the viewpoint of the SSDR hypothesis, both because the original learning involved an active avoidance task rather than noncontingent CS-US pairings, and because the required task in the absence of shock was continued holding of the bar rather than discrete responses. Bar holding is, of course, a form of freezing. In possibly the only acquired-drive study requiring barpressing, Baron (1959) found that experimental animals performed no better than pseudoconditioning controls. In an unpublished experiment from our laboratory, rats failed to learn to touch a mesh screen to terminate an aversive CS, though the operant level was high enough to guarantee exposure to the CS-offset contingency. It is possible that acquired drive experiments have succeeded at all only because the correct response has usually been a flight SSDR.

\section{REFERENCES}

Baron, A. Functions of the CS and US in fear conditioning. Journal of Comparative and Physiological Psychology, 1959, 52, 591-593.

Bolles, R. C. Species-specific defense reactions and avoidance learning. Psychological Review, 1970, 77, 32-48.

Bolles, R. C. The avoidance learning problem. In G. H. Bower (Ed.). The psychology of learning and motivation (Vol. 6). New York: Academic Press, 1972.

Bolles, R. C., \& Grossen, N. E. Effects of an informational stimulus on the acquisition of avoidance behaviors in rats. Journal of Comparative and Physiological Psychology, 1969, 68, 90:99.

Bolles, R. C., Stokes, L. W., \& Younger, M. S. Does CS termination reinforce avoidance behavior? Journal of Comparative and Physiological Psychology, 1966. 62, 201-207. 
Brown, J. S., \& JACoBs, A. The role of fear in the motivation and acquisition of responses. Journal of Experimental Psychology, 1949. 39, 747.759.

KING, M. G. Stimulus generalization of conditioned fear in rats over time: Olfactory cues and adrenal activity. Journal of Comparative and Physiological Psychology, 1969, 69, 560-600.

Masterson, F. A. Is termination of a warning signal an effective reward for the rat? Journal of Comparative and Physiological Psychology, 1970, 72, 471-475.

Masterson, F. A., \& Campbell, B. A. Techniques of electric shock motivation. In R. D. Myers (Ed.), Methods in psychology: Laboratory techniques in neuropsychology. New York: Academic Press, 1972.

MCAllister, W. R., \& McAllister, D. E. Role of the CS and of apparatus cues in the measurement of acquired fear. Psychological Reports, 1962, 11, 749-756.

MCAllister, W. R., \& McAllister, D. E. Increase over time in the stimulus generalization of acquired fear. Journal of Experimental Psychology, 1963, 65, 576-582.

MCAllister, W. R., \& MCAllister, D. E. Behavioral measurement of conditioned fear. In F. R. Brush (Ed.), Aversive conditioning and learning. New York: Academic Press, 1971.

Miller, N. E. Studies in fear as an acquirable drive: I. Fear as motivation and fear-reduction as reinforcement in the learning of new responses. Journal of. Experimental Psychology, 1948, 38, 89-101.
Miller, N. E., \& Weiss, J. M. Effects of the somatic or visceral responses to punishment. In B. A. Campbell \& R. M. Church (Eds.). Punishment and aversive behavior. New York: AppletonCentury-Crofts, 1969.

Mowrer, O. H. On the dual nature of learning: A reinterpretation of "conditioning" and "problem-solving." Harvard Educational Review, 1947, 17, 102-148.

Robinson, H. B. Persistence of a response in the apparent absence of motivation. Journal of Experimental Psychology, 1961, 61, 480-488.

SANTos, J. R. The influence of amount and kind of training on the acquisition and extinction of avoidance responses. Journal of Comparative and Physiological Psychology, 1960, 53, 284-289.

SCHOENFELD, W. N. An experimental approach to anxiety, escape, and avoidance behavior. In P. H. Hock \& J. Zubin (Eds.), Anxiety. New York: Grune \& Stratton, 1950.

THEIOS, J. Simple conditioning as two-stage all-or-none learning. Psychological Review, 1963, 70, 403-417.

Trapold, M. A., Blehert, S. R., \& Sturm, T. A. Failure to find a response persisting in the apparent absence of motivation. Journal of Experimental Psychology, 1965, 69, 538-540.

(Received for publication June 24, 1976; revision accepted November $2,1976$. 